\title{
Prevalência de trombofilias congênitas em pacientes com síndrome antifosfolípide primária
}

\author{
Prevalence of genetic thrombophilic in primary antiphospholipid syndrome \\ Jozélio Freire de Carvalho ${ }^{1^{*}}$, Nilton Sales Rosa Neto², Celia Cassaro Strunz ${ }^{2}$ \\ ${ }^{1}$ Professor Adjunto Visitante do Instituto de Ciências da Saúde da Universidade Federal da Bahia (ICS/UFBA).; ${ }^{2}$ \\ Afiliação da Universidade de São Paulo
}

A síndrome antifosfolípide primária (SAFP) é caracterizada por eventos trombóticos e perdas gestacionais associadas à presença de anticorpos antifosfolípides. A combinação de dois ou mais fatores trombofílicos aumenta o risco de tromboses. ${ }^{1-5} \mathrm{O}$ presente trabalho teve por objetivo avaliar a prevalência de outros fatores trombofílicos genéticos ou adquiridos na SAFP e verificar se existe associação clínica relevante.

Pesquisou-se numa coorte de 62 pacientes $(88,9 \%$ mulheres; idade média: 39,3 anos) com diagnóstico de SAFP (critérios de Sapporo), a presença de outros fatores trombofílicos, quais sejam: hiper-homocisteinemia $(\mathrm{HH})$ pelo método de quimioluminescência; deficiência de proteína S (DPS) através da quantificação funcional por método cronométrico; deficiências de proteína $C$ (DPC) e antitrombina III (DATIII) através da quantificação funcional por substrato cromogênico; e a pesquisa da mutação G20210A do gene da protrombina (MGP) por reação em cadeia da polimerase (PCR), seguida por digestão com enzima de restrição Hind III e pesquisa da mutação Q506 do gene do fator $V$ (fator $V$ de Leiden $-F V L$ ), por PCR seguida por digestão com enzima de restrição $\mathrm{Mnl}$ I.

Foram encontrados três (19\%) pacientes com FVL na forma heterozigota em 16 pesquisados. $\mathrm{HH}$ foi encontrada em 2/40 (5\%); DATIII em 1/31 (3,2\%); DPC em 7/33 (21\%); e DPS em 8/32 (32\%). Não foram encontradas MGP nos 14 pacientes em que foi pesquisada. Verificou-se também que se comparando os grupos de SAFP isolada com aqueles de SAF combinada a fatores de trombofilia, verificou-se que a idade da primeira apresentação de trombose ou perda gestacional foi significativamente menor no grupo
SAFP isolada (30,4 vs. 39 anos, $P=0,018)$. Por outro lado, não se observou diferenças significantes entre as freqüência de eventos arteriais (isquemia de xtremidades, AVCI), venosos (TVP, embolia pulmonar) e obstétricos entre os pacientes com SAFP isolada e SAF combinada. Os grupos também não diferiram em relação à frequenciad e anticardiolipina IgG, IgM e anticoagulante lúpico ( $P>0,05)$.

Em conclusão, pacientes com SAFP podem ser portadores de outras trombofilias em até um terço dos casos, principalmente devido à deficiência de proteínas anticoagulantes e o evento clínico trombótico ou obstétrico aparece mais tardiamente do que no grupo de pacientes com SAF com outras trombofilias.

\section{REFERÊNCIAS}

1. FORASTIERO, R. et al. The combination of thrombophilic genotypes is associated with definite antiphospholipid syndrome. Haematologica, Pavia, v. 6, p. 735-741, 2001.

2. GALLI, M., et al. The $\mathrm{G} 1691 \rightarrow \mathrm{A}$ mutation of factor $\mathrm{V}$, but not the G20210 $\rightarrow$ A mutation of factor II or the $\mathrm{C677} \rightarrow \mathrm{T}$ mutation of methylenetetrahydrofolate reductase genes, is associated with venous thrombosis in patients with lupus anticoagulants. Br. j. haematol., Ocford, v. 108, p. 865-870, 2000.

3. BERTOLACCINI, M. L., et al. Prothrombin mutation is not associated with thrombosis in patients with antiphospholipid syndrome. Thromb. Haemost., Stuttgart, v. 80, p. 202-203, 1998.

4. AMES, P.R. et al. Thrombophilic genotypes in subjects with idiopathic antiphospholipid antibodies: prevalence and significance. Thromb. Haemost., Stuttgart, v. 79, p.46-49, 1998.

5. TASSIES, D. et al. The $4 G / 5 G$ polymorphism of the type 1 plasminogen activator inhibitor gene and thrombosis in patients with antiphospholipid syndrome. Arthritis. rheum., Atlanta, v. 43, p. 2349-2358, 2000.
Submetido em: 08/09/2017

Aceito em: 13/10/2017 